\title{
Evaluation of The Degree of Remineralization of Subclinical Carious Lesions Using Chitosan and Conventional Remineralizing Agents
}

\author{
(An in vitro Study)
}

\author{
Khalid Mohamed Noaman, Walaa Mohamed Al-Samoly, Ahmed Abul-Khair Hassan Al-Hariri* \\ Department of Operative Dentistry, Faculty of Dental Medicine, Al-Azhar University (Boys) Cairo \\ * Corresponding author: Ahmed Abul-Khair Hassan Al-Hariri, Mobile: (+20)01010631460,
}

E-mail: ahmedelharery50@gmail.com

\begin{abstract}
Background: Dental caries remains to be the most common oral disease, caused by the unbalance between demineralization effect of bacteria and remineralization process. In the early phase of caries, this balance can be restored and the demineralization effect reversed using an enhanced approach to remineralization.

Objective: The aim of the study is directed to evaluate the degree of demineralization and remineralization in subclinical carious lesion using chitosan and conventional remineralizing agent.

Materials and methods: A total number of 40 sound non-carious human anterior teeth were collected from oral surgery clinic, free of cracks and any developmental defects, were used in this study in age range (20-40) years old. Teeth were stored in distilled water at room temperature until use. The teeth were divided into four main groups (10 teeth each).

Results: In the present study specimens treated with chitosan after six months storage time (the best result) recorded the highest mean value of remineralization while fluoride record the lowest mean value of remineralization (the worst result) through the remineralizing agents chitosan, casein, and fluoride. The specimens subjected to Diagnodent fluorescent reading proved that for all remineralizing agents (chitosan, casein and fluoride) and also control group the remineralization to tooth structure was increased by increasing the storage time.

Conclusion: Chitosan is considered a valuable biomimetic remineralizing agent. Mineral precipitation to tooth structures by using remineralizing agents is a continuous dynamic process.
\end{abstract}

Keywords: Demineralization, Remineralization, Subclinical carious lesions, Chitosan, Conventional remineralizing.

\section{INTRODUCTION}

So far, fluoride treatment remains to be the traditional remineralizing strategy for early enamel caries. Enamel remineralization using fluoride and its delivery methods have been studied extensively ${ }^{(1)}$. However, despite the predominant beneficial effect of fluoride on enamel remineralization; dental fluorosis induced by excessive intake of fluoride could not be ignored $^{(2)}$.

Fluoride adversely affects tooth development either through interactions with the developing ameloblast or the intracellular matrix ${ }^{(3)}$. Therefore, the administration of fluoride-containing dental products in children should be reviewed carefully. Also fluoride's mechanism of action is only topical within a reach of a few $\mu \mathrm{m}$ into enamel respectively into the subsurface carious lesion ${ }^{(4)}$.

Based on this knowledge, it is possible to develop a biomimetic. Remineralizing strategy is a methodology that imitates the natural process of mineralization by mimicking the biomineralization process. Non-classical crystallization pathway suggested that metastable amorphous precursors of hydroxyapatite (HAP) are involved in the natural mineralization process of dental hard tissues by directly transforming into HAP crystals ${ }^{(5)}$. In addition, noncollagenous proteins, such as amelogenin which chelate calcium ions as functional domains, and mediates biomineralization of dental hard tissues by serving as nucleators ${ }^{(6)}$.

Casein phosphopeptide (CPP) obtained from milk is such an analogue of the proteins involved in biomineralization of teeth. CPP contains clusters of phosphorylated seryl residues and thus can stabilize amorphous calcium phosphate (ACP) through the formation of nano-complexes ${ }^{(7,8)}$.

CPP-ACP provided a reservoir of calcium and phosphate ions to maintain a state of super-saturation with respect to HAP on enamel surface. The release of the mineral ions from this reservoir results in significant remineralizing effect on enamel subsurface lesion ${ }^{(9)}$.

Chitosan is a linear co-polymer of glucosamine. Its derivatives have emerged as a new class of novel biomaterials due to their versatile biological activity, excellent biocompatibility and complete biodegradability ${ }^{(9,10)}$.

Free Pchi molecules showed the inhibitory activity on the formation of calcium phosphate deposits in solution ${ }^{(8)}$. Thus, Pchi could be used to stabilize ACP to form the nano-complexes of PchiACP for remineralizing enamel subsurface lesion based on the biomimetic strategy. 


\section{AIM OF THE STUDY}

The aim of the study is directed to evaluate the degree of demineralization and remineralization in subclinical carious lesion using chitosan and conventional remineralizing agent.

Under the following variables:

1- Remineralizing agent:

1.1 Using phosphorylated chitosan (Pchi).

1.2 Casein phosphopeptide.

1.3 Fluoridated toothpaste.

2- Different storage times:

2.1 Three months storage time.

2.2 Six months storage time.

\section{MATERIALS AND METHODS}

I- Materials:

The following materials were used in this study (table 1, 2)

1- Demineralizing solution containing $(1.5 \mathrm{mM}$ $\mathrm{CaCl}_{2}, 0.9 \mathrm{mM} \mathrm{KH}_{2} \mathrm{PO}_{4}, 50 \mathrm{mM} \mathrm{CH}_{3} \mathrm{COOH}$, and $3 \mathrm{mM} \mathrm{NaN}_{3}$ were prepared with $\mathrm{pH} 4.8$ ).

2- Chitosan in the form of phosphorylated chitosan and amorphous calcium phosphate (Pchi-ACP) as a remineralizing agent.

3- Casein phosphopeptide-amorphous calcium phosphate (CPP-ACP) in the form of tooth mousse paste as a remineralizing agent.

4- Fluoride in the form of sodium fluoride $(\mathrm{NaF})$ as a remineralizing agent.

5- Artificial saliva solution was prepared in Faculty of Pharmacy, Al-Azhar University.

Table (1): Materials used in the study:

\begin{tabular}{|c|c|c|c|}
\hline & Material & Composition & $\begin{array}{l}\text { Manufacture and } \\
\text { website }\end{array}$ \\
\hline 1 & $\begin{array}{l}\text { Phosphorylated } \\
\text { chitosan and } \\
\text { amorphous calcium } \\
\text { phosphate } \\
\text { (Pchi-ACP) }\end{array}$ & $\begin{array}{l}\text { (Pchi-ACP ) prepared by adding } \mathrm{CaCl}_{2} \text { and } \\
\mathrm{K}_{2} \mathrm{HPO}_{4} \text { into Pchi-ACP solution }(0.5 \% \mathrm{w} / \mathrm{v}) \text { in } \\
\text { sequence. } \\
\text { The final concentrations of calcium and phosphate } \\
\text { ions were } 10 \text { and } 6 \mathrm{mM} \text {, respectively }\end{array}$ & $\begin{array}{l}\text { Oxford laboratory } \\
\text { reagent } \\
\text { www.oxfordlabch } \\
\text { em.com }\end{array}$ \\
\hline 2 & $\begin{array}{l}\text { GC Tooth } \\
\text { Mousse }\end{array}$ & $\begin{array}{l}\text { Pure water, glycerol, CPP-ACP, d-sorbitol, xylitol, } \\
\mathrm{CMC}-\mathrm{Na}, \text { propylene glycol, } \mathrm{H}_{2} \mathrm{O}, \mathrm{SiO}_{2}, \mathrm{TiO}_{2} \text {, } \\
\mathrm{ZnO}, \mathrm{H}_{3} \mathrm{PO}_{4}, \mathrm{MgO}_{2} \text {, guar gum, sodium saccharin, } \\
\text { ethyl p-hydroxybenzoate, butyl p-hydroxybenzoate } \\
\text { and propyl p-hydroxybenzoate. }\end{array}$ & $\begin{array}{l}\text { GC International, } \\
\text { Itabashi- Ku, } \\
\text { Tokyo, Japan. } \\
\text { www.recaldent.co } \\
\text { m }\end{array}$ \\
\hline 3 & Topex Neutral PH & $\begin{array}{l}\text { Sodium fluoride }(0.9 \% \text { fluoride ion from } 2 \% \text { sodium } \\
\text { fluoride) purified water, cabopol } 974 \text { pnfl carbomer } \\
\text { homopolymer type b, xanitham gum, disodium } \\
\text { phosphate, anhydrous, sodium hydroxide, artificial } \\
\text { strawberry flavor, benzoic acid, sodium saccharin, } \\
\text { methyl paraben. }\end{array}$ & $\begin{array}{l}\text { Sultan Healthcare, } \\
\text { USA } \\
\text { www.sultane.com }\end{array}$ \\
\hline
\end{tabular}

$($ Pchi-ACP $)=$ phosphorylated chitosan and amorphous calcium phosphate

CPP-ACP = Casein phosphopeptide - Amorphous calcium phosphate.

$\mathbf{C M C}=$ Carboxymethyl cellulose 


\section{Selection and grouping of teeth:}

A total number of 40 sound non-carious human anterior teeth were collected from oral surgery clinic, free of cracks and any developmental defects, were used in this study in age range (20-40) years old. The teeth were washed under running water to remove blood and debris, scaled to remove calculus and remnants of periodontal tissue and polished with eugenol free fine pumice and soft rubber cups rotating at low speed under water coolant. Teeth were stored in distilled water at room temperature until use. The distilled water was changed daily.

The teeth were divided into four main (A) groups $(\mathrm{N}=10)$ according to the remineralizing agent;

Group A1: control.

Group A2: teeth were treated using phosphorylated chitosan (Pchi).

Group A3: teeth were treated using casein phosphopeptide (CPP-ACP) "Tooth Mousseag".

Group A4: teeth were treated by soft toothbrush (Oral-B) with fluoridated mouth wash (Topex) for three minutes three times daily.

Each main group was further subdivided into two groups $(B)\left(n_{=} 5\right)$ according to the storage period in artificial saliva:

(B1): teeth were evaluated after 3 months' $(3 \mathrm{~m})$ storage time.

(B2): teeth were evaluated after 6 months' $(6 \mathrm{~m})$ storage time.

Table (2): Variables of the study:

\begin{tabular}{|l|l|l|}
\hline Variable & Symbol & Referring to \\
\hline \multirow{4}{*}{$\begin{array}{l}\text { Remineralizing } \\
\text { agents }\end{array}$} & A1 & Control \\
\cline { 2 - 3 } & A2 & $\begin{array}{l}\text { Phosphorylated chitosan } \\
\text { and amorphous calcium } \\
\text { phosphate (Pchi-ACP) }\end{array}$ \\
\cline { 2 - 3 } & A3 & (CPP-ACP) \\
\cline { 2 - 3 } $\begin{array}{l}\text { Storage } \\
\text { times }\end{array}$ & B4 & Fluoride \\
\cline { 2 - 3 } & B2 & Three months \\
\hline
\end{tabular}

Table (3): Factorial design and variables interaction:

\begin{tabular}{|l|c|c|c|}
\hline \multirow{2}{*}{$\begin{array}{c}\text { Remineralizing } \\
\text { agents }\end{array}$} & \multicolumn{3}{|c|}{ Storage times } \\
\cline { 2 - 4 } A1 & B1 & B2 & \\
\hline A2 & (N=5) & A1 B2 (N=5) & $\mathbf{1 0}$ \\
\hline A3 & $\begin{array}{r}\text { A2 B1 } \\
(\mathrm{N}=5)\end{array}$ & A2 B2 (N=5) & $\mathbf{1 0}$ \\
\hline A4 & $\begin{array}{r}\text { A3 B1 } \\
(\mathrm{N}=5)\end{array}$ & A3 B2 (N=5) & $\mathbf{1 0}$ \\
\hline Total & $\begin{array}{r}\text { A4 B1 } \\
(\mathrm{N}=5)\end{array}$ & A4 B2 $(\mathrm{N}=5)$ & $\mathbf{1 0}$ \\
\hline
\end{tabular}

I- Preparation of specimens
Preparation of specimens for remineralization:

The freshly extracted 40 intact human anterior teeth were stored in distilled water until used. The solution was changed every 24 hours. The crowns of all teeth were separated from the roots by a diamondcoated band saw under continuous water cooling, then stored in artificial saliva consisting of $(0.4 \mathrm{~g} \mathrm{NaCl}$, $0.4 \mathrm{~g} \mathrm{KCl}, 0,6 \mathrm{~g} \mathrm{CaCl}_{2}, 0.6 \mathrm{~g} \mathrm{NaH}_{2} \mathrm{PO}_{4}, 4 \mathrm{~g}$ urea, $4 \mathrm{~g}$

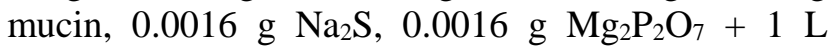
distilled water) at $\mathrm{pH} 7$.

\section{A- Fabrications of the moulds:}

A specially fabricated circle plastic mould of internal diameter $10 \mathrm{~mm}$ and $20 \mathrm{~mm}$ in height was fabricated. A separating medium was used to coat the internal surface of the mould. The mould was filled with self-curing acrylic resin, the base of the mould rested on a glass slab in order to obtain a flat smooth surface base. Each crown was embedded horizontally in middle of the mould containing self-cure acrylic resin in dough stage while the lingual surface embedded in resin and leaving about two $\mathrm{mm}$ from the labial surface projecting above the surface of the mould using caliber (Fig. 1). Then the labial surface of all the teeth was painted with nail varnish except two mm square in the middle of the crown (mesio distally and cervico incisally).

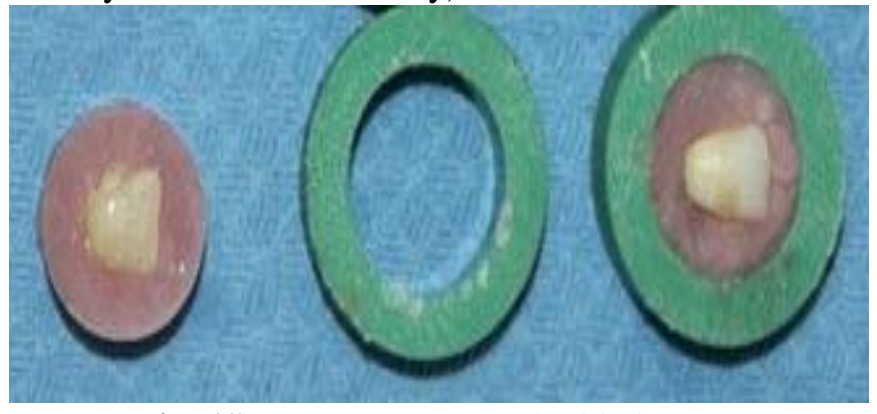

Fig. (1): Crowns were embedded horizontally in middle of the mould.

\section{B- Enamel white spot lesion formation:}

The labial surface of each specimens were treated by the demineralizing solution $\left(1.5 \mathrm{mM} \mathrm{CaCl}_{2}, 0.9 \mathrm{mM}\right.$ $\mathrm{KH}_{2} \mathrm{PO}_{4}, 50 \mathrm{mM} \mathrm{CH} \mathrm{COOH}_{3} \mathrm{COnd} 3 \mathrm{mM} \mathrm{NaN}_{3}$ ) with $\mathrm{pH}$ 4.8. The teeth immersed into that solution (one sample $/ 30 \mathrm{~mL}$ ) for 7 days at $37^{\circ} \mathrm{C}$ in a shaker $(50 \mathrm{rpm})$ to prepare enamel subsurface lesion (Fig. 2).

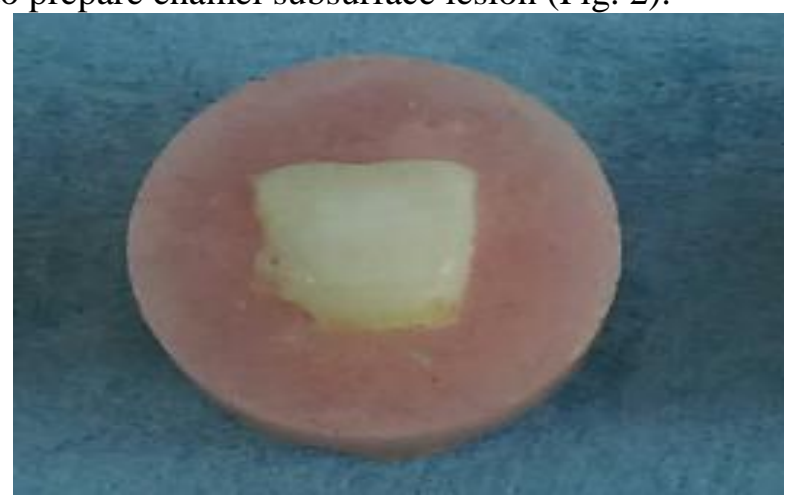

Fig. (2): White spot lesion. 


\section{C- Surface treatments:}

In group (A1): 10 specimens were immersed in artificial saliva, which was changed daily.

In group (A2): Remineralization treatments were carried out by brushing the labial surfaces of specimens by a soft toothbrush and with minimum pressure; brushing procedures were carried out for three minutes three times daily with a phosphorylated chitosan and amorphous calcium phosphate (Pchi$\mathrm{ACP}$ ). These samples were evaluated at 3 and 6 months using Diagnodent pen 2190.

In subgroup (A3): the labial surfaces of specimens were brushed manually by a soft toothbrush and with minimum pressure; brushing procedures were carried out three times daily with tooth mousse a CPP-ACPcontaining paste for three minutes then immersed in artificial saliva. These samples were investigated at 3 and 6 months using Diagnodent pen 2190.

In Subgroup (A4): the surfaces were brushed with Topex Neutral $\mathrm{pH}$ containing sodium fluoride for 3 minutes then immersed in artificial saliva. These samples were investigated at 3 and 6 months using Diagnodent pen 2190.

Mineral content assessment:
Energy Dispersive X-Ray Analysis (EDAX assessment): 40 specimens; 10 untreated, 10 treated by phosphorylated chitosan amorphous calcium phosphate (Pchi-ACP), 10 treated by (CAP-CPP) and 10 treated by fluoride, were subjected to surface analysis (for minerals presence or absence and their percentage, especially calcium and phosphorus) by energy dispersive aanalysis X-Ray (EDAX). EDAX spectrum images were acquired with an EMiSPEC vision integrated acquisition system. Data were recorded within an average of 6 minutes for each specimen.

\section{Statistical analysis:}

The mean and standard deviation values were calculated for each group in each test. Data were explored for normality using Kolmogorov-Smirnov and Shapiro-Wilk tests, and data showed parametric (normal) distribution. One-way ANOVA followed by Tukey post hoc test was used to compare between more than two groups in non-related samples. The significance level was set at $\mathrm{P} \leq 0.05$. Statistical analysis was performed with IBM ${ }^{\circledR}$ SPSS ${ }^{\circledR}$ version 20 for Windows.

\section{RESULTS}

I) A)Effect of remineralizing agent on the degree of remineralization assessment by EDAX: A.1 Degree of remineralization at control group (Table 4):

Table (4): The mean, standard deviation (SD) values of control of remineralizing agents on mineral precipitation at different storage time different groups.

\begin{tabular}{|c|c|c|c|c|c|c|c|}
\hline \multirow{3}{*}{ Variables } & \multicolumn{7}{|c|}{ Control } \\
\hline & \multicolumn{2}{|c|}{ Baseline (N=10) } & \multicolumn{2}{|c|}{ After 3 m (N=5) } & \multicolumn{2}{|c|}{ After 6 m (N=5) } & \multirow[t]{2}{*}{ p-value } \\
\hline & Mean & SD & Mean & SD & Mean & SD & \\
\hline $\mathrm{Ca}$ & $53.72^{c}$ & 3.11 & $60.93^{b}$ & 0.62 & $63.68^{a}$ & 1.97 & $<0.001 *$ \\
\hline $\mathbf{P}$ & $46.28^{a}$ & 3.11 & $39.07^{b}$ & 0.62 & $36.32^{c}$ & 1.97 & $<0.001 *$ \\
\hline $\mathrm{Ca} / \mathrm{P}$ & $1.16^{\mathrm{c}}$ & 0.15 & $1.55^{b}$ & 0.04 & $1.76^{\mathrm{a}}$ & 0.16 & $<0.001 *$ \\
\hline
\end{tabular}

Means with different letters in same raw indicate significant difference $(\mathrm{p}<0.05)$

\section{A.2 Degree of remineralization at chitosan group (Table 5):}

Table (5): The mean, standard deviation (SD) values of chitosan of remineralizing agents on mineral precipitation at different storage time different groups.

\begin{tabular}{|l|l|l|l|l|l|l|l|}
\hline \multirow{3}{*}{ Variables } & \multicolumn{9}{|c|}{ Chitosan } & \multirow{2}{*}{ p-value } \\
\cline { 2 - 8 } & Baseline & After 3 m & After 6 m & \\
\cline { 2 - 8 } & Mean & SD & Mean & SD & Mean & SD & \\
\hline $\mathbf{C a}$ & $59.72^{\mathrm{c}}$ & 2.29 & $70.99^{\mathrm{b}}$ & 1.53 & $79.28^{\mathrm{a}}$ & 1.57 & $<\mathbf{0 . 0 0 1}{ }^{*}$ \\
\hline $\mathbf{P}$ & $40.28^{\mathrm{a}}$ & 2.29 & $29.00^{\mathrm{b}}$ & 1.53 & $20.72^{\mathrm{c}}$ & 1.57 & $<\mathbf{0 . 0 0 1}$ \\
\hline $\mathbf{C a} / \mathbf{P}$ & $1.53^{\mathrm{c}}$ & 0.09 & $2.43^{\mathrm{b}}$ & 0.20 & $3.83^{\mathrm{a}}$ & 0.40 & $<\mathbf{0 . 0 0 1}$ \\
\hline
\end{tabular}

Means with different letters in same raw indicate significant difference $(\mathrm{p}<0.05)$ 
A.3 Degree of remineralization at casein group (Table 6):

Table (6): The mean, standard deviation (SD) values of casein of remineralizing agents on mineral precipitation at different storing time different groups.

\begin{tabular}{|l|c|c|c|c|c|c|c|}
\hline \multirow{2}{*}{ Variables } & \multicolumn{9}{|c|}{ Casein } & \multirow{2}{*}{ p-value } \\
\cline { 2 - 8 } & \multicolumn{2}{|c|}{ Baseline } & \multicolumn{2}{c|}{ After 3 m } & \multicolumn{2}{c|}{ After 6 m } & \\
\cline { 2 - 8 } & Mean & SD & Mean & SD & Mean & SD & \\
\hline Ca & $58.96^{\mathrm{c}}$ & 2.61 & $70.30^{\mathrm{b}}$ & 1.72 & $74.86^{\mathrm{a}}$ & 1.97 & $<\mathbf{0 . 0 0 1}^{*}$ \\
\hline $\mathbf{P}$ & $41.04^{\mathrm{a}}$ & 2.61 & $29.50^{\mathrm{b}}$ & 1.86 & $25.14^{\mathrm{c}}$ & 1.97 & $<\mathbf{0 . 0 0 1} *$ \\
\hline $\mathbf{C a} / \mathbf{P}$ & $1.41^{\mathrm{c}}$ & 0.14 & $2.35^{\mathrm{b}}$ & 0.17 & $2.99^{\mathrm{a}}$ & 0.32 & $<\mathbf{0 . 0 0 1} *$ \\
\hline
\end{tabular}

Means with different letters in same raw indicate significant difference $(\mathrm{p}<0.05)$

\section{A.4 Degree of remineralization at fluoride group:}

Table (7): The mean, standard deviation (SD) values of fluoride of remineralizing agents on mineral precipitation at different storing time different groups.

\begin{tabular}{|c|c|c|c|c|c|c|c|}
\hline \multirow{3}{*}{ Variables } & \multicolumn{7}{|c|}{ Fluoride } \\
\hline & \multicolumn{2}{|c|}{ Baseline } & \multicolumn{2}{|c|}{ After 3 m } & \multicolumn{2}{|c|}{ After $6 \mathrm{~m}$} & \multirow[t]{2}{*}{ p-value } \\
\hline & Mean & SD & Mean & SD & Mean & SD & \\
\hline $\mathbf{C a}$ & $55.86^{\mathrm{c}}$ & 2.86 & $68.40^{\mathrm{b}}$ & 1.86 & $69.21^{\mathrm{a}}$ & 1.15 & $<0.001^{*}$ \\
\hline $\mathbf{P}$ & $44.14^{\mathrm{a}}$ & 2.86 & $31.60^{\mathrm{b}}$ & 1.86 & $30.81^{\mathrm{c}}$ & 1.13 & $<0.001 *$ \\
\hline $\mathrm{Ca} / \mathrm{P}$ & $1.26^{\mathrm{c}}$ & 0.15 & $2.15^{b}$ & 0.17 & $2.22^{\mathrm{a}}$ & 0.13 & $<0.001 *$ \\
\hline
\end{tabular}

Means with different letters in same raw indicate significant difference $(\mathrm{p}<0.05)$

I) B) Effect of storage time on the degree of remineralization assessment by EDAX:

B .1 Degree of remineralization at base line storage time: (Table 8)

Table (8): The mean, standard deviation (SD) values of baseline of remineralizing agents on mineral precipitation of different groups.

\begin{tabular}{|c|c|c|c|c|c|c|c|c|c|}
\hline \multirow{3}{*}{ Variables } & \multicolumn{9}{|c|}{ Baseline } \\
\hline & \multicolumn{2}{|c|}{ Control (N=??) } & \multicolumn{2}{|c|}{ Chitosan (N?? } & \multicolumn{2}{|c|}{ Casein (N?? } & \multicolumn{2}{|c|}{ Fluoride (N?? } & \multirow[t]{2}{*}{ p-value } \\
\hline & Mean & SD & Mean & SD & Mean & SD & Mean & SD & \\
\hline Ca & $53.72^{\mathrm{c}}$ & 3.11 & $59.72^{\mathrm{a}}$ & 2.29 & $58.96^{\mathrm{ab}}$ & 2.61 & $55.86^{\mathrm{bc}}$ & 2.86 & $<0.001 *$ \\
\hline $\mathbf{P}$ & $46.28^{a}$ & 3.11 & $40.28^{c}$ & 2.29 & $41.04^{\mathrm{bc}}$ & 2.61 & $44.14^{\mathrm{ab}}$ & 2.86 & $<0.001 *$ \\
\hline $\mathrm{Ca} / \mathrm{P}$ & $1.16^{\mathrm{c}}$ & 0.15 & $1.53^{\mathrm{a}}$ & 0.09 & $1.41^{\mathrm{ab}}$ & 0.14 & $1.26^{\mathrm{bc}}$ & 0.15 & $<0.001 *$ \\
\hline
\end{tabular}

Means with different letters in same raw indicate significant difference $(\mathrm{p}<0.05)$

B .2 Degree of remineralization at three month storage time: (Table 9)

Table (9): The mean, standard deviation (SD) values after 3 months of remineralizing agents on mineral precipitation of different groups.

\begin{tabular}{|c|c|c|c|c|c|c|c|c|c|}
\hline \multirow{3}{*}{ Variables } & \multicolumn{9}{|c|}{ After 3 months } \\
\hline & \multicolumn{2}{|c|}{ Control } & \multicolumn{2}{|c|}{ Chitosan } & \multicolumn{2}{|c|}{ Casein } & \multicolumn{2}{|c|}{ Fluoride } & \multirow[t]{2}{*}{ p-value } \\
\hline & Mean & SD & Mean & SD & Mean & SD & Mean & SD & \\
\hline $\mathbf{C a}$ & $60.93^{c}$ & 0.62 & $70.99^{a}$ & 1.53 & $70.30^{\mathrm{a}}$ & 1.72 & $68.40^{b}$ & 1.86 & $<0.001 *$ \\
\hline $\mathbf{P}$ & $39.07^{\mathrm{a}}$ & 0.62 & $29.00^{c}$ & 1.53 & $29.50^{c}$ & 1.86 & $31.60^{b}$ & 1.86 & $<0.001 *$ \\
\hline $\mathrm{Ca} / \mathrm{P}$ & $1.55^{\mathrm{c}}$ & 0.04 & $2.43^{\mathrm{a}}$ & 0.20 & $2.35^{\mathrm{a}}$ & 0.17 & $2.15^{\mathrm{b}}$ & 0.17 & $<0.001 *$ \\
\hline
\end{tabular}

Means with different letters in same raw indicate significant difference $(\mathrm{p}<0.05)$ 
B .3 Degree of remineralization at six month storage time (Table 10)

Table (10): The mean, standard deviation (SD) values after 6 months of remineralizing agents on mineral precipitation of different groups.

\begin{tabular}{|c|c|c|c|c|c|c|c|c|c|}
\hline \multirow{3}{*}{ Variables } & \multicolumn{9}{|c|}{ After 6 months } \\
\hline & \multicolumn{2}{|c|}{ Control } & \multicolumn{2}{|c|}{ Chitosan } & \multicolumn{2}{|c|}{ Casein } & \multicolumn{2}{|c|}{ Fluoride } & \multirow[t]{2}{*}{ p-value } \\
\hline & Mean & SD & Mean & SD & Mean & SD & Mean & SD & \\
\hline $\mathbf{C a}$ & $63.68^{d}$ & 1.97 & $79.28^{\mathrm{a}}$ & 1.57 & $74.86^{b}$ & 1.97 & $69.21^{c}$ & 1.15 & $<0.001 *$ \\
\hline $\mathbf{P}$ & $36.32^{\mathrm{a}}$ & 1.97 & $20.72^{d}$ & 1.57 & $25.14^{\mathrm{c}}$ & 1.97 & $30.81^{b}$ & 1.13 & $<0.001 *$ \\
\hline $\mathrm{Ca} / \mathrm{P}$ & $1.76^{\mathrm{d}}$ & 0.16 & $3.83^{\mathrm{a}}$ & 0.40 & $2.99^{\mathrm{b}}$ & 0.32 & $2.22^{\mathrm{c}}$ & 0.13 & $<0.001 *$ \\
\hline
\end{tabular}

Means with different letters in same raw indicate significant difference $(\mathrm{p}<0.05)$

II) Diagnodent reading: (Table 11)

Table (11): The mean, standard deviation (SD) values of Diagnodent of remineralizing agents on mineral precipitation at different storage time and different groups.

\begin{tabular}{|c|c|c|c|c|c|c|c|}
\hline \multirow{3}{*}{ Variables } & \multicolumn{7}{|c|}{ Diagnodent } \\
\hline & \multicolumn{2}{|c|}{ Baseline } & \multicolumn{2}{|c|}{ After 3 m } & \multicolumn{2}{|c|}{ After 6 m } & \multirow[t]{2}{*}{ p-value } \\
\hline & Mean & SD & Mean & SD & Mean & SD & \\
\hline Control & $17.10^{\mathrm{a}}$ & 2.47 & $15.60^{b}$ & 2.27 & $14.50^{c}$ & 2.92 & $<0.001 *$ \\
\hline Chitosan & $18.30^{\mathrm{a}}$ & 1.34 & $11.00^{\mathrm{b}}$ & 1.49 & $5.80^{\mathrm{c}}$ & 1.03 & $<0.001 *$ \\
\hline Casein & $18.40^{\mathrm{a}}$ & 1.35 & $12.10^{b}$ & 1.37 & $8.20^{c}$ & 0.79 & $<0.001 *$ \\
\hline Fluoride & $18.30^{\mathrm{a}}$ & 1.83 & $13.20^{b}$ & 1.03 & $8.90^{c}$ & 1.20 & $<0.001 *$ \\
\hline p-value & \multicolumn{2}{|c|}{0.334 ns } & \multicolumn{2}{|c|}{$<0.001 *$} & \multicolumn{2}{|c|}{$<0.001^{*}$} & \\
\hline
\end{tabular}

Means with different letters in same raw indicate significant difference $(\mathrm{p}<0.05)$

\section{DISCUSSION}

Casein phosphopeptide functions in biomimetic mineralization of human enamel (11, 12) stabilize calcium, phosphate, and hydroxide ions, prevent spontaneous precipitation of calcium phosphate, and promote enamel subsurface lesion remineralization. Zhang et $\boldsymbol{a l} .{ }^{(13)}$ who effectively used phosphorylated chitosan and amorphous calcium phosphate (Pchi$\mathrm{ACP})$ as biomimetic remineralizing agent, found that the representative micro-CT cross-section images before and after remineralization for 3 months showed the changes in mineral profile over 3-month period in representative samples from the control and experimental groups. In the control group samples did not show remineralization, as there was no significant changes in the mineral profile. This was further verified by the quantitative results of mineral loss and rate of remineralization. In the experimental groups, both fluoride and Pchi-ACP treatments led to evident changes in the mineral profiles over 3-month remineralization.

While Borges et al. (14) effectively used remineralizing gels after bleaching. In their study seventy bovine incisors were divided into three groups. They stored the samples in artificial saliva, application of a fluoride gel and application of a combination of calcium and fluoride gel. The specimens were stored in artificial saliva for 7, 15 and 30 days and enamel micro hardness was evaluated. They found that that the storage in artificial saliva didn't cause a significant difference in enamel micro hardness during the evaluated periods $(7,15$ and 30 days). Also they observed no alterations in intact enamel micro hardness stored in artificial saliva. Although a remineralization effect of artificial saliva in bleached enamel was reported.

The effect of remineralizing agent on the degree of Remineralization

Yamaguchi et $\boldsymbol{a l} .^{(\mathbf{1 5})}$, proposed using the chitosan hydrogel for enamel remineralization in a supersaturated solution. Beltrame et $\boldsymbol{a l}^{\left({ }^{(16)}\right.}$ used solution of phosphorylated (AP)-Chi to regenerate an ordered enamel-like tissue through preserved mineralized collagen surface.

In the present study it was found that chitosan had the highest value as a biomimetic remineralizing agent and fluoride had the lowest value as a biomimetic remineralizing agent. These findings were in accordance with Ruan $\boldsymbol{e t} \boldsymbol{a l} .{ }^{\left({ }^{17}\right.}$ who effectively used amelogenin-chitosan (CS-AMEL) hydrogel to repair the artificial incipient caries by re-growing oriented crystals and reducing the depth of the lesions. 
Tschoppe et al. (18), who effectively used chosen, toothpastes containing nano-hydroxyapatite (n-HAp) toothpastes and amine fluoride toothpastes on remineralization of bovine enamel dentine, found that the fluoride toothpaste displayed the lowest remineralizing effects on both hard tissues, along with an increase in lesion depths.

On other hand our research is in disagreement with Zhang et al. ${ }^{(13)}$ who effectively used phosphorylated chitosan and amorphous calcium phosphate (Pchi$\mathrm{ACP}$ ) as biomimetic remineralizing agent. They found that remineralizing effect of Pchi-ACP on enamel lesions was similar to that of fluoride. However, the remineralizing rate of Pchi-ACP treatment was significantly higher than that of fluoride treatment. This contrast is because they used scanning electron microscope to scan surface morphology of the partially demineralized enamel sections before and after remineralization.

\section{The effect of storage time on the degree of remineralization}

Tschoppe et al. ${ }^{(18)}$ used toothpastes containing nanohydroxyapatite (n-HAp) and amine fluoride remineralizing bovine enamel and dentine. They evaluated the differences in mineral loss before and after storage/treatment micro radiographically. Calcium arising from storage solution should have followed a concentration gradient, thus leading to a remineralizing effect in deeper lesion parts ${ }^{\left({ }^{(19)}\right.}$.

In the present study it was found that six months storage time for chitosan group had the highest mean value and three months storage time for fluoride had lower value than six months and base line storage time for fluoride group had the lowest value. These findings were in accordance with Zhang et al. ${ }^{\left({ }^{(13)}\right.}$ who effectively used phosphorylated chitosan and amorphous calcium phosphate (Pchi-ACP) as biomimetic remineralizing agent. They found that the representative micro-CT cross-section images before and after remineralization for 3 months showed the changes in mineral profile over 3-month period in representative samples from the control and experimental groups. In the control group samples did not show remineralization, as there were no significant changes in the mineral profile. This was further verified by the quantitative results of mineral loss and rate of remineralization. In the experimental groups, both fluoride and Pchi-ACP treatments led to evident changes in the mineral profiles over 3-month remineralization.

Also our research is in agreement with Thierens $\boldsymbol{e t}$ al. (20) who effectively used casein phosphopeptidestabilized amorphous calcium phosphate (CPP-ACP), or CPP-ACP in combination with fluoride (CPPACPF) on artificial white spot lesions (WSLs) after 6 and 12 weeks. The changes were analyzed using Diagnodent $(\mathrm{KaVo})$ and scanning electron microscope (SEM). They found that CPP-ACP and CPP-ACPF in combination with a conventional tooth paste (1450 ppm F) reduced the extent and increased the mineral content of in vitro subsurface caries lesions. An application period of up to 12 weeks of CPP-ACPF showed superior results compared to a shorter application period (6 weeks). The latter emphasizes the importance of prolonged use in order to reduce the white spot lesion.

But our research is in disagreement with Borges et al. (14) who effectively used remineralizing gels after bleaching. They stored the samples in artificial saliva, application of a fluoride gel and application of a combination of calcium and fluoride gel. The specimens were stored in artificial saliva for 7, 15 and 30 days and enamel micro hardness was evaluated.

Diagnodent is an appropriate device for detection of demineralization processes in smooth enamel lesions.

Bahrololoomi et al. ${ }^{(21)}$ performed a laser fluorescence (LF) analysis using Diagnodent at baseline, after demineralization, and remineralization they found that there was a significant difference between superficial micro hardness SMH values at baseline, after demineralization and after remineralization. Also, a statistically significant difference was observed between LF values in these three stages. The LF values increased after demineralization and then decreased after remineralization, and the SMH values decreased after demineralization and increased after remineralization. There was an inverse relationship between SMH and LF only at baseline and after demineralization, but not after remineralization. So The Diagnodent values increased after demineralization and then decreased after remineralization.

Pinelli et al. ${ }^{(22)}$ the aimed in their study to verify the drying effect on the reproducibility of Diagnodent (Dd) devices to detect caries-like lesions. Three areas were created in each of the 34 bovine incisors: sound (S), demineralized (DE) and remineralized (RE). One examiner measured each area with two Dd devices (denominated $\mathrm{X}$ and $\mathrm{Y}$ ), twice under humid, and twice under dry. The results indicated that under dry conditions, it is possible to replace Dd devices to detect caries-like lesions in free smooth surfaces in vitro. Drying for $10 \mathrm{~s}$ is recommended to assure reliability in the diagnosis of caries lesions.

In the present study It was found that six months storage time for chitosan group had the highest mean value of remineralization and the lowest number of reading and three months storage time for chitosan had lower value than six months, and base line storage time for fluoride group had the lowest mean value of remineralization and the highest number of reading. Diagnodent reading in our study is in accordance with Thierens et al. (20) who effectively used casein 
phosphopeptide-stabilized amorphous calcium phosphate (CPP-ACP), or CPP-ACP in combination with fluoride (CPP-ACPF) on artificial white spot lesions (WSLs) after 6 and 12 weeks. The changes were analyzed using Diagnodent $(\mathrm{KaVo})$ and scanning electron microscope (SEM). They found that CPP-ACP and CPP-ACPF in combination with a conventional tooth paste (1450 ppm F) reduced the extent and increased the mineral content of in vitro subsurface caries lesions. An application period of up to 12 weeks of CPP-ACPF showed superior results compared to a shorter application period (6 weeks). The latter emphasizes the importance of prolonged use in order to reduce the white spot lesion.

\section{CONCLUSION}

1. Chitosan is considered a valuable biomimetic remineralizing agent.

2. Mineral precipitation to tooth structures by using remineralizing agents is a continuous dynamic process.

3. Considering the factor treatment, the greatest remineralizing value was found in chitosan group, and the lowest remineralizing value was found in fluoride group.

\section{REFERENCES}

1. Featherstone JDB (2000): The science and practice of caries prevention. J. Am. Dent. Assoc., 131: 887-899.

2. Ten C (2008): Remineralization of deep enamel dentine caries lesions. Aust. Dent. J., 53(3):281-5.

3. Fomon SJ, Ekstrand J, Ziegler EE (2000): Fluoride intake and prevalence of dental fluorosis: trends in fluoride intake with special attention to infants. J. Public Health Dent., 60: 131-9.

4. Tanna N, Kao E, Gladwin M et al. (2009): Effects of sealant and self-etching primer on enamel decalcification. Part I: An in-vitro study. Am. J. Orthod. Dentofac. Orthop., 135, 199-205.

5. Gebauer D, Cölfen H (2011): Prenucleation clusters and non-classical nucleation. Nano Today, 6: 564-584.

6. George A, Veis A (2008): Phosphorylated proteins and control over apatite nucleation, crystal growth, and inhibition. Chem. Rev., 108: 4670-93.

7. Cross KJ, Huq NL, Reynolds EC (2007): Casein phosphopeptides in oral health--chemistry and clinical applications. Curr. Pharm. Des., 13: 793-800.

8. Andrew CA, Khor E, Hastings GW (1998): The influence of anionic chitin derivatives on calcium phosphate crystallization. Biomaterials, 19: 1309-16.
9. Rinaudo M (2006): Chitin and chitosan: Properties and applications. Prog. Polym. Sci., 31: 603-632.

10. Walsh LJ (2009): Contemporary technologies for remineralization therapies: A review. Int. Dent. SA., 11: 34-43.

11. Kumar VLN, Itthagarun A, King NM (2008): The effect of casein phosphopeptide-amorphous calcium phosphate on remineralization of artificial caries-like lesions: An in vitro study. Aust. Dent. J., 53: 34-40.

12.Jayarajan J, Janardhanam $P$, Jayakumar $P$ et al. (2011): Efficacy of CPP-ACP and CPP-ACPF on enamel remineralization - An in vitro study using scanning electron microscope and DIAGNOdent ${ }^{\circledR}$. Indian J. Dent. Res., 22: 77-82.

13.Zhang X, Li Y, Sun $X$ et al. (2014): Biomimetic remineralization of demineralized enamel with nanocomplexes of phosphorylated chitosan and amorphous calcium phosphate. J. Mater. Sci. Mater. Med., 25: 2619-2628.

14. Borges AB, Yui KC, D'Avila TC et al. (2010): Influence of remineralizing gels on bleached enamel microhardness in different time intervals. Oper. Dent., 35: $180-186$.

15. Yamaguchi I, Itoh S, Suzuki M et al. (2003): The chitosan prepared from crab tendons: II. The chitosan/apatite composites and their application to nerve regeneration. Biomaterials, 24: 3285-3292.

16. Beltrame APCA, Suchyta D, Abd Alraheam I et al. (2018): Effect of Phosphorylated Chitosan on Dentin Erosion: An in vitro Study. Caries. Res., 52: 378-386.

17. Ruan Q, Liberman D, Bapat R et al. (2015): Efficacy of amelogenin-chitosan hydrogel in biomimetic repair of human enamel in pH-cycling systems. J. Biomed. Eng. Informatics, 2: 119-128.

18. Tschoppe $P$, Zandim DL, Martus $P$ et al. (2011): Enamel and dentine remineralization by nanohydroxyapatite toothpastes. J. Dent., 39: 430-437.

19. Aoba T (2004): Solubility properties of human tooth mineral and pathogenesis of dental caries. Oral Diseases, 10: 249-257.

20. Thierens LAM, Moerman S, Elst CV et al. (2019): The in vitro remineralizing effect of CPP-ACP and CPP-ACPF after 6 and 12 weeks on initial caries lesion. J. Appl. Oral Sci., 27: e20180589.

21. Bahrololoomi Z, Musavi SA, Kabudan M (2013): In vitro evaluation of the efficacy of laser fluorescence (DIAGNOdent) to detect demineralization and remineralization of smooth enamel lesions. J. Conserv. Dent., 16: 362-366.

22.Pinelli C, Loffredo L de CM, Serra MC (2010): Effect of drying on the reproducibility of DIAGNOdent to detect caries-like lesions. Braz. Dent. J., 21: 405-410. 